\title{
The Advantage and Disadvantage Analysis of "Three Old" Transformation for Guangzhou City
}

\author{
Luzhen Liu, Weiji Zhou \\ School of Management, Guangdong University of Technology, Guangzhou, China \\ Email: aprtree@163.com
}

Received 15 December 2015; accepted 25 January 2016; published 28 January 2016

Copyright ( 2016 by authors and Scientific Research Publishing Inc.

This work is licensed under the Creative Commons Attribution International License (CC BY). http://creativecommons.org/licenses/by/4.0/

(c) (i) Open Access

\section{Abstract}

This paper analyzes the content, operation methods and implementation effectiveness of "three old" transformation in Guangzhou city, and expounds the "three old" transformation policy through taking urban village reconstruction as an example and combines with game theory analysis method, which sum up the advantage and exist problem of Guangzhou "three old" transformation. It concludes that the "three old" transformation in Guangzhou does not cause more harm than goodness, and a fully implementation is good for urban renewal and protects the interests of the villagers. Transformation is both an opportunity and a challenge. An initiative of people, coordination of different participants in the process of implementation, respect and suggestion from villagers, strength supervision and management are required during implementation. Meanwhile, this paper puts forward number of shortcomings of the current policy, in hope of that this can be taken as an reference by the further implementation of the "three old" transformation.

\section{Keywords}

Guangzhou City, “Three Old” Transformation, Policy, Advantage and Disadvantage Analysis

\section{Introduction}

Since the reform and opening up, Guangdong economic and social development has made great achievements, with the development of the social economy, the quantity of cultivated land is reducing sharply, which has been a serious threat to human survival environment and sustainable development. Guangzhou, being the capital of Guangdong Province, the model city of "three old" transformation, to further implement the provincial govern- 
ment "some opinions on promoting the reform of 'three old' to promote the intensive land use", to promote collaboration development of urban and rural areas, and to achieve strictness protection of arable land and intensive land usage, the Guangdong government produces "some opinions on promoting the reform of the 'three old' transformation on purpose of reducing the land usage”. According to the related spirits, Guangzhou carries out a large-scale "three old" transformation.

At present, there are lots of academic research on "three old" transformation model, and actually they mainly concentrate in the "three old" reform policy analysis, pattern analysis, planning and transformation of land usage. However, for the retrospection and benefits analysis of "three old” transformation, they are relatively less. Under this circumstance, this paper analyzes the "three old" transformation's content, implementation methods, policies, results and so on. And from the analysis, it summarizes up the pros and cons of "three old" transformation, hoping that this can provide a reference for the further implementation of "three old" transformation.

\section{Guangzhou City "Three Old" Reform Policy [1]-[3] Basic Situation}

\subsection{The Content of "Three Old" Transformation}

The word "three old" was first produced in Foshan, and it was used to refer to the old town, the old village and the old factory. The "old town" transformation mainly refers to: to the district, town, city center within the state-owned land housing crisis breaks or part of the structure is relatively good but lower standard of construction and environmental facilities of the old housing, historical and cultural blocks, retreat into three industrial land reform. The transformation of "old village" mainly refers to: the layout of the village, the village, the village, the village, the conditions are backward, or are included in the "village of land renovation" and other villages in the village to carry out rectification and transformation. Old factory transformation mainly refers to: in the town, the village is no longer the old plant for industrial use, transformation of land and by the National prohibition, elimination, safety and environmental protection do not pass the workshop [1]-[4].

The districts involved in "old town” reform includes YueXiu, HaiZhu, LiWan, TianHe, BaiYun, HuangPu, LuoGang district, and the transformation is mainly implemented in LiWan and HuangPu district; the number of villages involved in "old village” reform is 138, among of which BaiYun district reaches to 53 and the task of its transformation is the hugest, then it is Tian He district, in which an entire transformation should be implemented on those villages (total 52) to improve city function and upgrade the industrial structure; the factories involved in "old factory" reform are those factories have huge effect on environment, safety and also those not permitted and dangerous chemical factories. Such kind of factories totally takes up about 54 square kilometers and they are mainly in Li Wan and BaiYun district, and BaiYun district has the most renovation projects on such old factories.

\subsection{The Implementation Method of "Three Old" Transformation}

According to the overall planning of land usage, urban overall planning, control and the "three old" reform plan, scientifically determine the scope of "three old" reform, to reform those units hinders the urban renewal, those unreasonable usage of land resources, those waste land. The government led and built the " $1+3+\mathrm{N}$ " of the "three old” reform planning system, according to which the reform is processed step by step. “Three old” reform is a dynamic process, and it should be linked up with the surrounding traffic planning, infrastructure planning.

"Old town" reform is led by the government, which adopts partial reconstruction, reform, historical and cultural protection and improvement, in accordance with the demolition of a fill a tax incentives and encourage social capital financing policy, monetary compensation, the nearest place, different places, such as relocation compensation. "Old village” transformation of the implementation of the wishes of the villagers, the government approval, including resettlement compensation, removed building, rehabilitation and delivery process. "Old factory" with the state-owned land, the village collective land reform, public transfer, public interest in the three models, in the premise of improving the history of land use, the village collective old plant can be transferred to the state, and incorporated into the village in the planning and co-ordination. Finally realize the urban renewal plan.

\subsection{Policies of "Three Old" Transformation}

Since 2010, Guangzhou has gone through 5 years' “three old” reform. Time flies, the center of Guangzhou’s "three old" reform changed according to the related policy. The data told that before 2012, the form mainly fo- 
cused on the amount in case of improving speed, however, after 2012 the reform focused on the "good" and based on "comprehensive performance" [5]. Related policies are depicted in Table 1.

Through an in-depth analysis of Guangzhou's "three old" reform policy, it is found that the key point it focued on includes urban renewal, historical heritage protection, land expropriation, transfer income, relocation compensation and so on. Moreover, the "three old" reform has its own unique and innovations such as: change the rural collective construction land into state-owned land, bits of flower arranging, sandwich according to the processing, protection of resettlement housing land supply, financial support and fund balance policy, tax preferential policy etc. Old village takes the largest proportion in "three old" reform, as a result the old village reform is the root of the success of the "three old" reform.

The characteristics of urban village in Guangzhou city are: first, the large scale of the village collective economy, most of the collective land, property rental as the main source of income (such as Tianhe district's hunting village, Shahe, Liwan district, Fangcun,, etc.), the intensiveness of market is high [6]. Secondly, the mess management and bad environment. Thirdly, along the road traffic trunk, metropolitan area "gold belt", uneven in between, a forest of many-storied buildings and city development, has formed a great contrast to (such as Tianhe district Shipai village, the Pearl River Metro Area Xian village). In land scarce, population gathering in Guangzhou, with the continuous appreciation of the city land, the golden section of the city village, the villagers property value has become quite considerable, the villagers "landlord" wealth accumulation, in the face of such an attractive pie, most of the villagers refused to easily compromise on the demolition, unless the government proposed a more generous compensation benefits.

Therefore, during the process, the negotiation never stops between the government and the villagers in Guangzhou city. In "three old" reform, the most important part of "old town" reform is how to rebuild and place the historical collective economic buildings. As a result, the village collective property is faced with the use of land development, whether or not to accept the transformation, the government dismantled or re construction, is to give the demolition of a compensation, or only provide the relative compensation for the cost of resettlement and other issues, the government and the village collective to carry out the game, to take full information static

Table 1. Mainly policy related to "three old” transformation for Guangzhou in recent years.

\begin{tabular}{|c|c|}
\hline Time & Policy Name \\
\hline 2008-05-26 & $\begin{array}{l}\text { Opinions on improving the policy issues concerning the transformation of the } \\
\text { "rural residents" and "villages in the city" }\end{array}$ \\
\hline 2009-08-25 & Some opinions on promoting the reform of "three old" and promoting the intensive land use \\
\hline 2009-12-31 & Opinion on accelerating the transformation of "three old" \\
\hline $2010-07-26$ & $\begin{array}{l}\text { On the promotion of urban industry and the transformation of the old factory "will work in the } \\
\text { construction planning and management requirements of the relevant notice" }\end{array}$ \\
\hline 2011-04-09 & $\begin{array}{l}\text { Notice on speeding up the handling of the "three old" reconstruction project involves the } \\
\text { improvement of the procedures of the historic sites }\end{array}$ \\
\hline 2011-05-13 & About Guangzhou city, three old transformation management decentralization views \\
\hline 2011-12-01 & $\begin{array}{c}\text { Guangzhou city “three old” reconstruction project land transfer revenue collection } \\
\text { and use of management approach }\end{array}$ \\
\hline 2012-05-10 & Circular on the development of rural collective land registration in Guangzhou \\
\hline 2012-06-06 & Supplementary opinion on accelerating the three old transformation work \\
\hline $2012-09-28$ & $\begin{array}{l}\text { Opinions on strengthening the supervision of the construction of comprehensive reform } \\
\text { projects in the old village }\end{array}$ \\
\hline $2012-11-27$ & “Three old” project transformation plan approval management regulations \\
\hline 2013-05-10 & On the full implementation of Xian Cun reform announcement \\
\hline 2014-11-27 & $\begin{array}{c}\text { Notice of the implementation of the housing levy and compensation on the state-owned } \\
\text { land in Guangzhou }\end{array}$ \\
\hline 2015-04-02 & $\begin{array}{l}\text { Guangzhou Municipal People's Government Office on accelerating the implementation of the } \\
\text { comprehensive improvement of rural land in our city }\end{array}$ \\
\hline
\end{tabular}


game, the corresponding game [7] [8] case shown in Table 2.

From the table, $\mathrm{H}$ represents the potential gains after the demolition of the land in the future can be obtained; $\mathrm{Z}$ said the government expenditure compensation in the demolition process; B said the government for noncompliance with no proof of ownership of collective economy property development in the demolition reconstruction when the villagers refused to accept the government negotiations with the villagers eventually transformation spending; $\mathrm{Z}$ said for the net income of the land reform and support the development of the village collective economic expenditure; D said the villagers accept the compensation income obtained from transformation; DC said the villagers in the existing collective economy property in income (income to maintain the status quo); F said the villagers in non-compliance with the development of the proceeds; A said the villagers refused to take various measures to maintain the government reform expenditure; $\mathrm{T}$ said the demolition and reconstruction cost of government expenditure; ZC said the government for rehabilitation costs; the government said C For the compensation of the cost of the construction of the land grant, S said the government's land revenue loss caused by the use of the land development of the villagers. From the crossing method, there is no Nash equilibrium in the game, the final value of the two sides of the game, on behalf of the two sides of the income, on behalf of the government's revenue, the right of the village collective income.

Further analysis of the game process, the first combination (H-T-Z-B-Z, D-DC) said the government in the village collective land, improve procedures for compliance under the condition to dismantle the collective property with other infrastructure purposes, the government due to the transformation of the economic and land revenue to $\mathrm{H}$, and before this all compensation and costs, so the government's net income is H-T-Z-B-Z; the villagers built in their legal development on collective property acquired by the government to reform compensation income D, after the transformation of lost property derived income is DC, so the villagers finally obtained in the first combination of net income to D-DC. In accordance with the above results can be the following three kinds of combinations. Through the analysis, we can find that there is no absolute winner in the two games, so the problem of the village in the city is still not resolved, the game between the government and the village is still ongoing, "three old" reform is still difficult.

Guangzhou city village reconstruction methods are summarized as follows: 1) to encourage investment in land transfer; 2) The implementation of the demolition of a free one, the tax relief and return of preferential policies; 3) eligible "villages in the city" land can be registered as state-owned land; 4) the government let the land of $60 \%$ of net income for the village collective development; 5) will be transferred to the village committee, the village collective economic organization for the joint-stock enterprises. In addition, there are old plants, the transformation of the old town, which is also facing the transformation of the villagers in the interests of the villagers, land expropriation, monetary compensation, resettlement and other issues, this work involves a wide range, and therefore have a lot of advantages and disadvantages.

\subsection{The Performance Results of "Three Old" Transformation}

Since the implementation of the "three old" reform in Guangzhou city in 2010, Liede, Lin He, Tangxia, Sanyuanli, Xian village, Pazhou 14 village has completed the transformation project approval work, Liede village, Huangpu village, Yu'an village has completed the transformation of old villages; donghaochong, lizhiwan has finished the old urban transformation; T.I.T Creative Park, Taigucang, 1850 Industrial Park has completed the transformation of the old plant, Datansha island wide paper kilometer is the implementation of the transformation of the three old transformation, the new " $1+3$ " policy document is the basic supporting documents drafted. 2015 is being implemented in the area of the renovation project has 13, with a land area of about $101 \mathrm{~km}^{2}$; the organization planning area reconstruction project 11 , with a land area of about $18 \mathrm{~km}^{2}$; the area of the previous

Table 2. Game between the government and village collective.

\begin{tabular}{|c|c|c|c|}
\hline & & \multicolumn{2}{|c|}{ Village collective (village collective economic organization, the villagers) } \\
\hline \multicolumn{2}{|c|}{ Game participants } & Compliance development land reform & $\begin{array}{l}\text { Unconventional development land } \\
\text { refuse transformation }\end{array}$ \\
\hline \multirow{2}{*}{$\begin{array}{l}\text { Government (municipal } \\
\text { government, district } \\
\text { government) }\end{array}$} & Dismantle & $(\mathrm{H}-\mathrm{T}-\mathrm{Z}-\mathrm{B}-\Delta \mathrm{Z}, \mathrm{D}-\mathrm{DC})$ & $(\mathrm{H}-\mathrm{Z}, \mathrm{F}-\mathrm{A})$ \\
\hline & Rehabilitation & (-ZC-C-B, D-DC) & $(-S, F-A)$ \\
\hline
\end{tabular}


study of the renovation project 20, with an area of about $17 \mathrm{~km}^{2}$.

Secondly, in recent years, Guangzhou three old transformation project to stimulate social investment of about about 3000 billion yuan, benefiting more than about 120 thousand people from the public, the old plant transformation will increase the green area of about 227 [5] $\mathrm{Hm}^{2}$, in addition, the government can get part of the proceeds of the transformation of the land. Not only stimulate economic growth, but also improve the city view, to promote the Guangzhou city renewal process.

\section{Advantages and Disadvantages of "Three Old" Reform in Guangzhou}

\subsection{The Advantages of "Three Old" Transformation}

1) Promote urban renewal, optimize the structure of urban functions and enhance the image of the city

"Three old" transformation of the ultimate goal is to carry out urban renewal, at present, Guangzhou city is in the important period of breaking the bottleneck of urban development, urban development can be used for land reserve shortage, planning to disperse disorderly, space layout confusion, population capacity is becoming saturated, space homogeneous phenomenon heavier, the body in the town as [9], so the city's taste quality is difficult to improve.

Through the "three old" reform, it clarifies the main categories of reform, and according to the relationship of different subjects it develops urban renewal method, which involves a variety of public facilities, green, transportation network. In this process, we can optimize the spatial structure of the city, improve the national comprehensive urban image, so that it can improve the ability of urban renewal in the beautiful, structure, content, level and comfort.

2) Respect for public opinion, scientific decision-making, and promote the integration of urban and rural development

Guangzhou city's "three old” reform, is not an arbitrary policy. From the beginning, the reform program incorprate the residents' willness and it protects the residents' the-right-to-know, reflects the scientific nature of government decision-making. "Three" reform policies put forward a new financing mode and organization mode, through the macro grasp, can the convergence of old and new policies and the division of responsibilities clear planning and division of labor, breaking the traditional single sector led structure, and promote the scientific decision-making, reduce the power lines to rent space. At the same time, in the transformation of the village collective can share or to sell the land to participate in the transformation of [10]. In this way, the farmers' income is more independent and market oriented, and share the benefits of reform. Through the "three old" reform, to give the villagers more property rights, to speed up the process of new urbanization, breaking the structure of urban and rural two yuan, and promote the integration of urban and rural development.

3) Adjust the industrial structure, the transformation of economic development mode

With the new urbanization progresses, the old factory village has gradually been surrounded by the city land, the original dilapidated industrial enterprises gradually adapt to the requirements of the times and face the fate of being eliminated. How to adjust the industrial structure, changing the mode of economic development has become an urgent problem to be solved. This policy has brought the opportunity for the development of new industries, "three old" into the new land, and increased the protection of housing construction, expanding the supply of real estate demand. By the end of 2014, Guangzhou city shantytowns 11,682 sets of affordable housing construction projects required to about 265.77 hectares, greatly promoting the real estate industry diversification; through the transformation of new industries to effectively boost investment and consumption growth, provide more jobs, to solve the problem of employment and industrial upgrading and transformation provides a good platform. Through the "three old" reform, the industrial structure adjustment of the industrial structure adjustment [11], which is used to transfer the industrial land to the third industrial structure, update the creative industry, research and development, can speed up the speed of urban renewal and the development of economic construction in Guangzhou.

4) Heritage of the history and culture, the protection of the ecological and traditional style of South of the Five Ridges

Guangzhou focus on promoting and inheriting the history and culture of the ancient city, but with the further expansion of the three old transformation, the inevitable original building to be changed, it may be completely, it may be a partial change, which has a certain impact on the residents of the home environment, cultural heritage. Guangzhou city "three old renovation" follow "focuses on the protection and weakening of residence, repair the 
old as the old, build a new old principle [1], put a lot of financial funds to support the protection of the ancient village and the historical and cultural blocks. Not only did not destroy the original historical and cultural customs building, also the essence of traditional and modern technology combine together, created a more perfect "spirit" is similar to the cultural heritage of [12], Guangzhou to display the vivid history and culture at home and abroad. Through the "three old" reform, to stimulate the villagers to protect the historical and cultural enthusiasm, the emergence of more unique folk art, in the economy led to the development of tourism in Guangzhou, in the spirit of the protection of the ecological and traditional style of South of the Five Ridges, and promote the harmony between man and nature.

\subsection{Some Problems of "Three Old" Transformation in Guangzhou}

1) In the implementation of the transformation process, prone to power rent-seeking, job crime and other issues

"Three old" transformation of the implementation process involves many aspects, especially in the sensitive part of the demolition, the government and the village collective major interests of different points. On the issue, the collection and placement of such procedures lack of open and transparent, the approval process is too simple, the supervision of the performance mechanism is not perfect, the right is too concentrated and other issues easily lead to the temptation to participate in the interests of the people involved in the reform, the use of policy loopholes and position to facilitate criminal [13], to the right of the space of rent-seeking. First, participants take false land area, fake property and government collusion to defraud relocation; second, government officials took advantage of his position to take bribes, illegal subcontracting; third, government benefit greatly, the village collective get the huge compensation, may be used for illegal modification such as improper use. Many villagers believe that the demolition will be able to make demands, get the huge compensation from the government, breed a variety of problems, challenges the authority of law. These behaviors have seriously affected the social stability and harmony, leading to the transformation of the work cannot be fair and fair, is bound to affect the quality of the three old transformation.

2) How to use the land

First of all, in accordance with the Guangzhou "three" reform policy, the old factory land "should be stored in the best" principle by the government to recover the land use rights to land reserves. In accordance with the law to recover the old factory land disposal mode, according to public welfare land standards to be compensated, the standard is what, the relevant policies are not clearly defined. Such as improper operation of the government, it is easy to lead to conflict. Secondly, gains in government purchasing and storage process by way of purchasing low price auction, the land sold gold standard by the benchmark price of the original 3\% to $4 \%$ of the benchmark price, developers get the rise in the cost of joint security resettlement housing prices also rose, the other three old parties dissatisfied, so "should be stored as storage" principle is also the slow transformation of the "three old" stumbling block "process". On the issue of land use, the government should have more understanding on the residents' wishes and reduce the conflicts of the land use.

3) Difficult balance between government and villagers interests

For a long time, the government and the villagers is the two main game, in the transformation process, the government and the owners are often diametrically opposed, the villagers tend to fight for their own interests and continue to bargain with the government. In the process of transformation and not all the villagers to buy government compensation scheme, the total "nail households" in order to seek greater benefits to the transformation of space. If the government and the negotiations succeed, it must pay a greater price of compensation. Similarly, the other villagers will have a sense of injustice and thus to follow their behavior, this cycle will undoubtedly increase the three old transformation of the cost of capital. The government is in the absolute initiative side position, has a directional thinking that stakeholders tend to government, even in the "three old" transformation in many special security policies and funds, it seems that in the village, is a lip-service? If the goods are not for the transformation? All sorts of concerns let them stop, the transformation of the enthusiasm is hit.

In addition, the ecological red line restricts the space of urban land expansion, the direct impact of the impact of the interests of the village [14]. Transformation is always a priority in the city center of the gold belt, and some remote, difficult to transform the small village because the profit is small to attract social funds and always be ignored. The villagers in a passive party, the interests of vulnerable to violations, the interests of the government and the villagers difficult to balance the problem. 
4) The slow progress of reconstruction, there needs to be wary of "unfinished"

Since the implementation of the "three old" reform in 2010, the "three old transformation" plan of Guangzhou city is only 5\%, and the completion of the situation is not ideal. With the current progress, it is difficult to complete the planning task. First of all, the three old transformation of this unique model, Guangdong is a model Province, so planning is still need to continue to update, planning and adjustment is inevitable. When the adjustment to make the premium is still in accordance with the original compensation standards, the villagers' income in the invisible, the villagers will be considered to develop the bad, unfair, violations of their rights and refused to accept the transformation. As a result of the "opinions", I personally think that due to the appropriate compensation to improve.

Secondly, the implementation and planning are uncoordinated. The adjustment of three old transformation in the planning level are basically starting from the regulatory loopholes, and planning in the replacement process is easy to profit benefit loophole, will lead to the transformation of high cost. Investigate its origin, mainly is from the bottom up and from the top to bottom, the method has no dynamic to combine.

In addition, the old plant transformation project can be carried out by the authority of the ownership, but when more than the time has not been completed the government has to continue to take over, the transfer payments can be appropriate to extend the project, the appropriate extension of the time in the end is how long, how many days to reform the process, these policies are not clearly defined. These are not sure to be the transformation of the project to the three old transformation of the future work is undoubtedly a huge impact, the government's workload is more difficult, directly led to the transformation process is stalled. Although Guangzhou may appear in city reconstruction project unfinished set "on the strengthening of the old village renovation project comprehensive rehabilitation resettlement fund supervision opinions", but the fund supervision only old village, the old factory has not been perfect, so as long as the transformation of the "three old" in the "unfinished" problem is inevitable the causes, so how to solve this problem still need to continue to explore.

\section{Conclusions}

Overall, the advantages of "three old" reform outweigh the disadvantages, although the transformation is difficult, the fruits of victory are sweet, and a good implementation of "three old" reform will benefit the villagers. For the villagers, their living environment improving and the local industrial structure upgrade as well. No one shows any interest in favor, and the popularity is driven by high yield. For the government, not only proves its planning, implementation of policy and service for the people, but also promotes the development of urban economy, and solves the problems left over by history.

Therefore, Guangzhou city's "three old” reform is an opportunity, but also is a challenge. It needs the effect of government, the village collective and developers. It requires us to fully absorb foreign experience, listen to the views of people, respect the wishes of the villagers to establish confidence; and coordinate the interests of all parties to strengthen supervision and inspection, to avoid large-scale conflicts. Consequently, the "three old" reform in Guangzhou city will achieve a major breakthrough and a smooth realization of the original intention.

\section{References}

[1] Guangzhou “Three Old” Reform Office (2013) Guangzhou “Three Old” Reform Policy Q \& A.

[2] Office of Legal Affairs of the People’s Government of Guangzhou Municipality (2009) Opinion on Accelerating the Transformation of "Three Old".

[3] Guangzhou Municipal People’s Government (2009) Guangzhou Municipal People’s Government on Promoting the Implementation of the Transformation of the Old City of Guangzhou City.

[4] Wang, L. (2015) Three Old Transformation Study-Taking Huangshi City as an Example. Chinese and Foreign Architecture, 1, 97-99.

[5] Lai, S.H. and Wu, J. (2013) Speed and Efficiency: A New Type of Guangzhou “Three Old” Reform Policy under the Background of New Urbanization. Planner, 5, 36-41.

[6] Jiang, H. and Zeng, X.N. (2011) Research on the Status Quo and Transformation of Villages in the City-Taking Liwan District as an Example of Guangzhou City. China Agricultural Press, Beijing.

[7] Zhang, Z.L and Wang Y.F. (2011) Analysis of Land Expropriation in China Based on Complete Information Dynamic Game Land Science in China. Land Science in China, 25, 49-53.

[8] Liu, Y.G., Huang, S.Q. and Yuan, Y. (2011) “Three Old” Reform Policy Analysis—Taking Dongguan City as an Ex- 
ample. City Observation, 2, 76-85.

[9] Zhou, X. and Fu, F.Y. (2011) Thinking about Urban Renewal Caused by “Three Old Transformation” in Guangdong Province. Modern Urban Research, 8, 82-89.

[10] Wang, X.W. (2010) The Experience and Practice of “Three old” Reform in Guangdong under the Transformation of Economic Development. Planning Innovation: 2010 Annual Meeting of Chinese Urban Planning, Vol. 9, Chongqing Press, 1-10.

[11] Ye, H.L. (2012) Investigation and Consideration about the "Three Old” Transformation in Guangdong. Territorial Resources, 6, 38-41.

[12] Qu, S.J. (2011) Research on the Protection and Utilization of Historical Culture in Guangzhou “Three old” Reform. City Observation, 2, 95-105.

[13] Liao, S.Q. (2010) On the Crime of “Three old” Reform. Law and Society, 11, 145-146.

[14] Teng, X. and Zou, P. (2014) “Three old” Transformation of Urban Villages in the City of the Plight and Countermeasures. Modern Urban Research, 2, 95-99. 